\title{
Insights on Ceramics as Dental Materials. Part II: Chemical Surface Treatments
}

\author{
Gary Willie Ho • Jukka Pekka Matinlinna
}

Received: 12 January 2011 / Accepted: 1 March 2011 /Published online: 30 March 2011

(C) The Author(s) 2011. This article is published with open access at Springerlink.com

\begin{abstract}
The purpose of surface treatment (conditioning) methods on dental ceramics is to improve the retention and bonding between the enamel or the dentin and ceramic veneer, with the help of resin composite luting cements. These types of surface treatments include chemically altering the surface of ceramics with some specific acidic etchants followed by applying a silane coupling agent (silane). The silane currently used in dentistry is 3-methacryloxypropyltrimethoxysilane, a hybrid organic-inorganic trialkoxy ester monomer, which is diluted in an acidified water-ethanol solvent system. Such silane primers are said to be pre-hydrolyzed. Some oxide ceramics with high crystalline content, such as alumina and zirconia, cannot be easily etched with acid etchants. They should be silica-coated and silanized prior to bonding. A silane coupling agent should be applied after silica-coating to the ceramic surface to achieve chemical bonding and the optimal durable bond strength.
\end{abstract}

Keywords Silane coupling agent · Silane $\cdot$ Silica-coating · Hydrofluoric acid · Acid etchants · Zirconia

\section{Surface Treatments on Dental Ceramics}

The direct bonding of ceramics to natural teeth is inadequate for dental use because ceramics do not have a natural affinity to teeth. Thus, to obtain sufficient adhesion, it is essential to etch the tooth enamel with phosphoric acid and the bonding surface of the ceramic is etched with an acid etchant so that luting resin cement can penetrate into the pores and the

G. W. Ho · J. P. Matinlinna $(\bowtie)$

Dental Materials Science, Faculty of Dentistry,

The University of Hong Kong,

Hong Kong, SAR, People's Republic of China

e-mail: jpmat@hku.hk material necessarily silanized to ensure good bonding between the ceramic veneer and luting resin cement as shown in Fig. 1 $[1,2]$. When the ceramic restoration is cemented with resin composite cement, the fracture resistance is increased [2]. In many in vitro studies, a resin composite is used as a substitute for enamel or dentin because of the similar biomechanical properties between them.

\section{Acid Etching in Bonding}

Acid etching is the most effective procedure in enhancing and retaining bond integrity between feldspar-based ceramic restoration and resin composite cement compared with sandblasting and grit-blasting the surface of ceramics [4]. By etching the ceramic surface with hydrofluoric acid, HF, a porous structure is created facilitating micromechanical retention between resin composite and ceramic: uncured flowable resin composite luting cement may penetrate into the porous structure [2]. A secondary function of etching is cleansing the ceramic surface by removing debris and unwanted oxides and thus, enhancing wettability of the ceramic substrate $[1,4,5]$. Examples of acid etchants include hydrofluoric acid, acidulated phosphate fluoride, and ammonium hydrogen difluoride. It has been claimed that etching is the most significant factor in improving bond strengths in dentistry [6].

\subsection{Hydrofluoric Acid Etching}

Hydrofluoric acid creates the porous structure on the ceramic surface by reacting with the silica matrix of the ceramic to form volatile $\mathrm{SiF}_{4}[4,7]$,

$$
\underset{\text { Hydrofluoric Acid }}{4 \mathrm{HF}(\ell)}+\underset{\text { Silica Matrix }}{\mathrm{SiO}_{2}(\mathrm{~s})} \rightarrow \underset{\text { Silicon Tetrafluoride }}{\mathrm{SiF}_{4}(\mathrm{~g})}+\underset{\text { Water }}{2 \mathrm{H}_{2} \mathrm{O}(\ell)}
$$




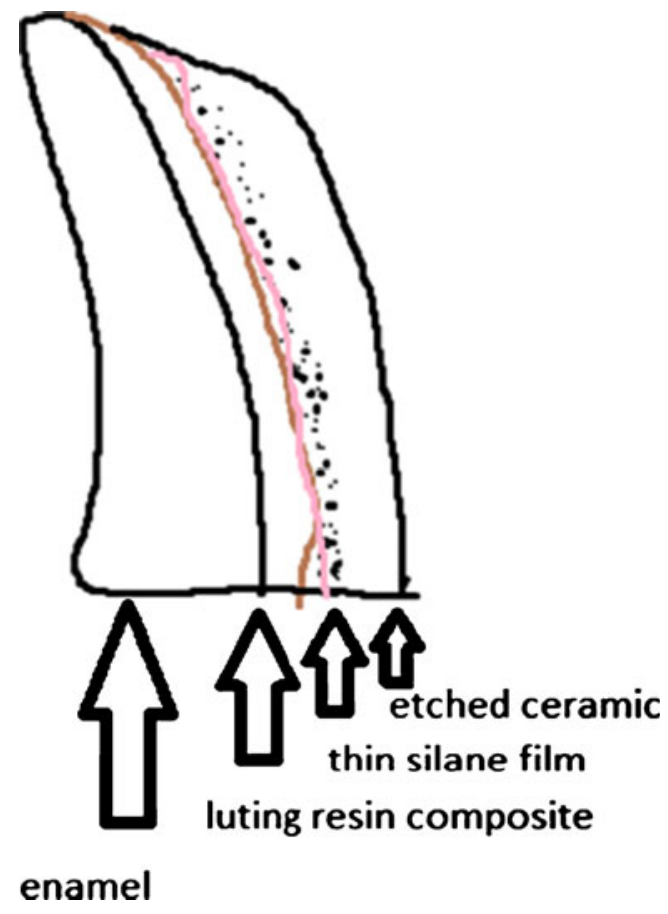

Fig. 1 An outline of a bonding system

Then, silicon tetrafluoride reacts further with the hydrofluoric acid again to form a soluble complex ion, hexafluorosilicate,

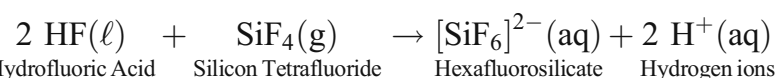

The hydrogen ions in the solution react with the hexafluorosilicate complex ion that can be rinsed off:

$$
\underset{\text { Hexafluorosilicate }}{\left[\mathrm{SiF}_{6}\right]^{2}(\mathrm{aq})}+\underset{\text { Hydrogen ions }}{2 \mathrm{H}^{+}(\mathrm{aq})} \rightarrow \underset{\text { Fluorosilic acid }}{\mathrm{H}_{2} \mathrm{SiF}_{6}(\ell)}
$$

By removing and dissolving the glassy phase matrix that contains silica, $\mathrm{SiO}_{2}$, silicates, $\mathrm{SiO}_{4}{ }^{4-}$, and leucite, $\mathrm{K}_{2} \mathrm{O} \cdot \mathrm{Al}_{2} \mathrm{O}_{3} \cdot 4$ $\mathrm{SiO}_{2}$, crystals, a deep porous structure with pore size of 3-4 $\mu \mathrm{m}$ is created. Boundary areas of silica in the ceramic matrix dissolve at a higher rate than those within the exposed grain $[4,6,8-10]$. The etched depth of feldspar-based ceramic is observed to increase with time: etching the surface for $5 \mathrm{~min}$ with hydrofluoric acid resulted in depth as deep as 5-7 $\mu \mathrm{m}$ and etching castable glass ceramic produced depth as deep as $10 \mu \mathrm{m}$ for $5 \mathrm{~min}$ [4]. An increase in concentration of hydrofluoric acid increases the roughness of the ceramic surface [14]. Ceramics etched with a higher concentration of hydrofluoric acid (52\%) for $1.5 \mathrm{~min}$ dissolved more of the glassy phase and produced uniformly crystalline patterns while lower concentration of hydrofluoric acid (20\%) dissolved more of the crystalline phase and displayed a more amorphous structure exhibiting relatively large porosity [6]. Hydrofluoric acid may attack ceramics such as leucite-reinforced, glassinfiltrated alumina, lithium disilicate, and low alumina ceramic
$[7,11]$. It has been reported that resin bonded to feldspar-based ceramics had significantly greater bond strengths than resin bonded to alumina [12].

Etching ceramic surfaces with $9.5 \%$ hydrofluoric acid for $1 \mathrm{~min}$ provides adequate roughness and etching for 4 min provides the desirable surface irregularities and roughness containing deep channels. Unfortunately, this study was only an observational study and no quantitative observations were recorded [8]. On the contrary, an in vitro study found that the optimum etching time to be $2 \mathrm{~min}$ using $5 \%$ hydrofluoric acid etching as evidenced by the highest mean shear bond strength after $24 \mathrm{~h}$ water storage at $37^{\circ} \mathrm{C}$, viz. $44.5 \pm 7.6 \mathrm{MPa}$, for feldspar-based ceramic bonded to resin composite. Anything greater than $3 \mathrm{~min}$ decreased the bond strength. A scanning electron microscope study revealed that ceramic surfaces etched between $2 \mathrm{~min}$ to $3 \mathrm{~min}$ resulted in rougher, deeper, and larger number of pore sites, thus, more resin can penetrate into the ceramic pores to provide micromechanical interlocking $[6,13]$. Etching for a prolonged period of time should be avoided because etching 5\% HF for $2.5 \mathrm{~min}$ had significantly higher shear bond strengths than $20 \mathrm{~min}$ [12]. The best advice is to follow the manufacturer's recommendations or, also a good rule of thumb is anywhere between $1 \mathrm{~min}$ to $2 \mathrm{~min}$ if no instructions are provided.

\subsection{Some Other Acidic Etchants}

Acidulated phosphate fluoride, APF, contains $1.23 \%$ fluoride ions. The fluoride ion is released from $\mathrm{NaF}$ and $\mathrm{HF}$ and the etchant is acidified by the addition of $0.1 \mathrm{M} \mathrm{H}_{3} \mathrm{PO}_{4}[15,16]$. These materials are described as gels that are thixotropic with no stable three-dimensional network [10]. Increasing etching time for APF is reported to increase the shear bond strength [17].

Ammonium hydrogen difluoride, $\mathrm{NH}_{4} \mathrm{HF}_{2}$, may be used as a glass etchant and as an intermediate for production of hydrofluoric acid [18]. $\mathrm{NH}_{4} \mathrm{HF}_{2}$ attacks the silica component of glass:

$\mathrm{SiO}_{2}+4 \mathrm{NH}_{4} \mathrm{HF}_{2} \rightarrow \mathrm{SiF}_{4}+4 \mathrm{NH}_{4} \mathrm{~F}+2 \mathrm{H}_{2} \mathrm{O}$

\subsection{Hydrofluoric Acid Etching vs. Other Etching Agents}

Etching feldspar-based ceramics with 23\% APF for $10 \mathrm{~min}$ is insufficient to generate the amount of micromechanical interlocking in comparison with $9.5 \%$ hydrofluoric acid etched for $4 \mathrm{~min}$. A scanning electron microscope showed a shallow and smooth homogenous surface with acidulated phosphate fluoride in contrast to a deep, three-dimensional lattice, and uniformly porous channels with hydrofluoric acid $[8,17,19]$. Hydrofluoric acid treatment exhibits more 
aggressive etching patterns and porous structures than acidulated phosphate fluoride etching [20]. Acidulated phosphate fluoride acts more superficially on the ceramic surface because it contains only a low concentration of hydrofluoric acid with few fluoride ions [8, 18, 21].

\subsection{Bond Strengths with Acid Etching}

In an in vitro study, feldspar-based ceramic surfaces etched with $9.6 \%$ hydrofluoric acid for $2 \mathrm{~min}$ and bonded to resin composite resulted in a statistically higher tensile bond strength than for surfaces etched with $4 \%$ acidulated phosphate fluoride for $2 \mathrm{~min}$ and $10 \% \mathrm{NH}_{4} \mathrm{HF}_{2}$ for $1 \mathrm{~min}$. Highly irregular surface patterns produced the highest bond strength as demonstrated by using hydrofluoric acid [19].

Among the five different surface conditioning treatments on leucite-reinforced ceramics, viz. with $9.5 \%$ hydrofluoric acid, 50\% phosphoric acid, 60\% phosphoric acid, $50 \mu \mathrm{m}$ air borne particle abrasion, and $250 \mu \mathrm{m}$ air borne abrasion, it was observed that $9.5 \%$ hydrofluoric acid produced the highest shear bond strength when luted with a resin composite to enamel, 14.7 $\pm 0.6 \mathrm{MPa}$, and bonded to dentin, $8.2 \pm 1.5 \mathrm{MPa}$. All specimens were treated with a silane coupling agent. The mean shear bond strength was almost $50 \%$ higher than the second highest group that was treated with a $60 \%$ phosphoric acid. The lowest mean shear bond strength obtained was a ceramic surface treated with $50 \%$ phosphoric acid bonded to enamel, 2.7 $\pm 0.8 \mathrm{MPa}$, and bonded to dentin, $1.5 \pm 0.1 \mathrm{MPa}$. It was observed that $9.5 \%$ hydrofluoric acid produced the roughest surface on leucitereinforced ceramics by using a surfanalyzer, which measures surface roughness by calculating the average height of irregularities from mean line within sampling mean length [22]. Reported microtensile bond strength values for lithium disilicate ceramics etched with $9.6 \%$ hydrofluoric acid for 2 min had a higher bond strength, 41.7 $\pm 6.7 \mathrm{MPa}$, than those etched with $4.0 \%$ acidulated phosphate fluoride for $2 \mathrm{~min}, 19.1 \pm 2.6 \mathrm{MPa}$ [23].

\subsection{Is Hydrofluoric Acid Unnecessary?}

It has been claimed that etching with hydrofluoric acid is unnecessary because of its toxicity. Hydrofluoric acid dissolves in the epithelial lining fluid to form a weak acid $\left(\mathrm{pK}_{\mathrm{a}}=3.8\right)$ and is toxic to the lungs and eyes. It is readily absorbed through the skin into the blood and may cause tissue necrosis and degeneration of bones. HF may cause severe burns on mucosa, eyes, and skin. The HF etching must take place in a dental lab and never intraorally. It is suggested to use as low concentration as possible, to neutralize hydrofluoric acid before disposing, and to keep hydrofluoric acid containers closed at all times when not in use $[24,25]$. One study suggested that unfilled resin bonded to ceramic with $9.5 \%$ hydrofluoric acid etching and $1.23 \%$ acidulated phosphate fluoride etching yielded similar etching patterns with similar depth and potential for microretention. There were no significant differences in mean bond strengths between etching with hydrofluoric acid or etching with acidulated phosphate fluoride on the ceramic surface. However, hydrofluoric acid etching still produced a higher overall mean bond strength compared to acidulated phosphate fluoride etching [18].

Another in vitro study reported that a durable bond between ceramic and resin can be obtained with gritblasting the ceramic surface only since the mean tensile bond strength was similar to hydrofluoric acid etching the ceramic surface. This result was observed before and after water storage in combination with thermocycling [26]. Kukiattrakoon et al. found that ceramics etched with either $1.23 \%$ acidulated phosphate fluoride for $7-10$ min or $9.6 \%$ hydrofluoric acid for $4 \mathrm{~min}$ bonded to resin composite didn't produce a significant difference in shear bond strengths between the two surface treatment approaches. Nevertheless, hydrofluoric acid etching for $4 \mathrm{~min}$ still yielded the highest shear bond strength, 17.64 $1.48 \mathrm{MPa}$, compared to acidulated phosphate fluoride etching, $17.33 \pm 1.43 \mathrm{MPa}$ [17]. It may be concluded that there are still far more studies achieving higher bond strengths between resin and ceramic with hydrofluoric acid etching than without.

\section{Silane Coupling Agents}

Silane coupling agents (silanes) are synthetic organicinorganic hybrid compounds with direct $\equiv \mathrm{C}-\mathrm{Si} \equiv$ bonds. They are silicon esters that may contain trialkoxysilane groups. They bond dissimilar materials together by forming a branched 3D siloxane (-Si-O-Si-) film between two materials [7, 11, 26]. Silanes are used as surface primer agents for adhesion promotion, a process called conditioning or priming. Conditioning can increase the critical surface energy of a surface. A high critical surface energy on the substrate surface and low surface tension of a liquid is desired because liquids will spread evenly onto the surface. Low energy contaminants such as oil and grease inhibit wetting and prevent adhesion. In order to achieve complete wetting, the adhesive must have low viscosity and the surface tension must be lower than the critical surface tension $\left(\gamma_{\mathrm{c}}\right)$ of the substrate surface [7]. For dental use, 3methacryloxypropyltrimethoxysilane monomers are diluted with an acidified solvent, usually ethanol, to produce ca. 1-2\% silane primers that then wet the substrate surface and reduce the surface tension of an etched ceramic so that resin composite cement can penetrate easily into the pores and adhere to the ceramic surface [2, 7, 8, 27, 28]. 
Moreover, silanes can act as mediators that bond two dissimilar materials together through a process called silanization. They are structured to have dual function monomers consisting of alkoxy groups that are hydrolyzed to react with the ceramic surface and methacrylate groups containing $\mathrm{C}=\mathrm{C}$ bonds that co-polymerize with the monomers of the resin composite matrix [11, 29]. In dentistry, silanes are indicated for veneering, prior to cementation of the ceramics, and before repairing ceramic/composite veneers. Most pre-activated silane products already contain activated silane oligomers that have been hydrolyzed but the disadvantage of pre-activated silane is a shorter shelf life $[2,7,11]$. For common activated dental silane products, the shelf life of silanes is usually $2-4$ years [30].

\subsection{The Chemistry Behind Silane Coupling Agents}

Tetrachlorosilane (silicon tetrachloride), $\mathrm{SiCl}_{4}$, is used as a precursor for the syntheses of functional silane monomers. It undergoes rapid hydrolysis:

$$
\mathrm{SiCI}_{4}(\ell)+2 \mathrm{H}_{2} \mathrm{O}(\mathrm{g} \text { or } \ell) \rightarrow \mathrm{SiO}_{2}(\mathrm{~s})+4 \mathrm{HCI}(\mathrm{g})
$$

The silane coupling agent used in dentistry is 3methacryloxypropyltrimethoxysilane, also known as $\gamma$ methacryloxypropyltrimethoxysilane or $\gamma$-MPS for short form (Fig. 2). It is usually dissolved and diluted with an ethanol-water solution, ca. 1-2\% and acetic acid is used to catalyze the reaction and $\mathrm{pH}$ is adjusted to 4-5 [7]. Typical silane coupling agents have three hydrolyzable alkoxy groups on a silicon atom [11].

The hydrophobic silane monomer (Fig. 2) has one backbone end that contains a non-hydrolyzable methacrylate group with a vinylic carbon-carbon double bond $\left(-\mathrm{CH}=\mathrm{CH}_{2}\right)$. The other end consists of relatively fast hydrolyzable alkoxy groups, usually due to kinetic reasons it is a methoxy group, $-\mathrm{O}-\mathrm{CH}_{3}$. After activation, the alkoxy groups become labile intermediates that hydrolyze. The silane ester groups, $-\mathrm{Si}-\mathrm{O}-$ $\mathrm{CH}_{3}$, form hydrophilic labile silanol groups, $\equiv \mathrm{Si}-\mathrm{OH}$, and a solvent is present to maintain coupling agent solubility $[7$, 30]. Monomeric or oligomeric silanols may react to form polysiloxane bonds $(-\mathrm{Si}-\mathrm{O}-\mathrm{Si}-)_{\mathrm{n}}$ with other surface silanols to create a complex 3D silane film [7, 31]. Several

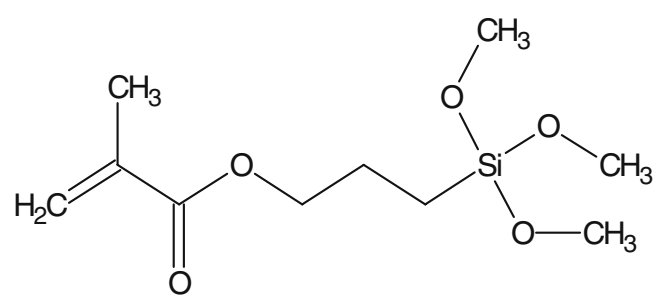

Fig. 2 3-methacryloxypropyltrimethoxysilane $(\gamma$-methacryloxypropyltrimethoxysilane) monolayers of silane film condense to form oligomeric siloxanols and these siloxanols condense again to form cross-linked structures that bond to the silica on the ceramic surface $[6,31]$. However, silane films are unstable in humid conditions [32]. Figure 3 shows a very brief and simplified version of the understood hydrolysis reaction.

The optimal thickness for strong bonding between silane and silica on the ceramic surface is estimated to be $10-20 \mathrm{~nm}$ $[7,33]$. Heat treatment on a silanized feldspar ceramic at $60^{\circ} \mathrm{C}$ for $60 \mathrm{~s}$ eliminates contaminants (such as water and alcohol) that decrease bonding sites on the ceramic surface and improve the shear bond strength between the resin and ceramic. The condensation reaction on the silane-silica interphase may proceed towards its completion and allow the formation of silane-silica covalent bonds [3, 11, 31]. A minimum drying (i.e. reaction) time of $3 \mathrm{~min}$ has been suggested for the application of a silane coupling agent to the ceramic surface in dentistry [34], however, it might be even only $1 \mathrm{~min}$, as suggested in vitro [35]. According to an in vitro study, storing pre-activated silane solution, viz. $2.5 \%$ 3-methacryloxypropyltrimethoxysilane with grade solvents of $2.5 \%$ acetic acid (catalyst) and $95 \%$ ethanol for various periods of time (15 min, $2 \mathrm{~h}, 1$ month, 6 months, and 1 year) showed no significant difference in the tensile bond strength of leucite-reinforced ceramic bonded to resin with a silane coupling agent [34]. A clear silane solution indicates usability while a milky or cloudy silane solution means that some chemistry with other elements has occurred and it is wise to dispose the solution [36]. Silane solutions can deteriorate over time and precipitate out of the solution to form a polymer without coupling properties [7, 13, 30].

\subsection{Bond Strengths After Silanization}

By silanizing the ceramic surface only, bond strength between the ceramic and the resin can improve [37, 38]. It was found in vitro that applying 3-methacryloxypropyltrimethoxysilane onto the ceramic surface bonded to resin composite resulted in significantly higher mean tensile bond strength values than by surface etching. Silanizing treatment only produced mean tensile bond values of $11.4 \pm 3.5 \mathrm{MPa}$ for leucitebased ceramics and $9.8 \pm 2.7 \mathrm{MPa}$ for alumina-reinforced ceramics. However, there was no control in the study to compare how much the bond strength improved without any treatments [19].

\section{Hydrofluoric Acid Etching Followed by Silanization}

There is a general, though not unanimous, agreement that hydrofluoric acid etching followed by silanization with 3methacryloxypropyltrimethoxysilane generates higher bond strengths than either treatment alone. Silanization is under- 

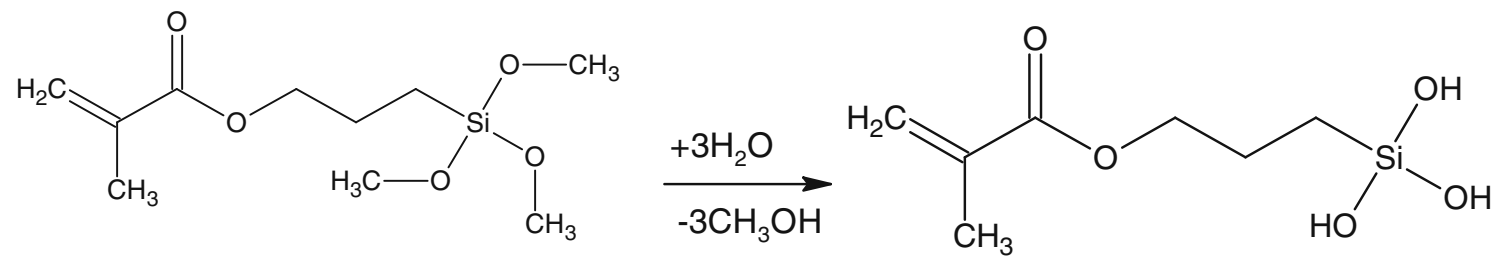

Fig. 3 A simplified version of the hydrolysis of $\gamma$ - methacryloxypropyltrimethoxysilane

stood to create hydrogen bonding and covalent bonding between the resin and the ceramic while etching provides the mechanical interlocking $[6,8,11,34,39,40]$.

\subsection{Bond Strengths with Etching and Silanization}

Treatments Without Any Storage Conditions

A combination of both etching and silanization treatments on feldspar-based ceramic bonded with resin composite yielded a shear bond strength of $18.6 \pm 1.8 \mathrm{MPa}$, in comparison to a shear bond strength of $15.6 \pm 0.9 \mathrm{MPa}$ for hydrofluoric acid etching as a treatment alone. Albeit, the bond strength difference was not statistically significant and the concentration of hydrofluoric acid used in the study was not mentioned [6]. Also observed was a significant improvement in the bond strength for resin composite bonded to leucite-based ceramics that was etched with $20 \%$ hydrofluoric acid and silanized. Shear bond strengths improved from $5.31 \pm 3.29 \mathrm{MPa}$ (no treatments) to $24.62 \pm 5.70 \mathrm{MPa}$ (etching plus silanization) [37]. It was found that etching with $9.6 \%$ hydrofluoric acid and silanizing bonded to resin composite achieved shear bond strength as high as $19.72 \pm$ $7.73 \mathrm{MPa}$. Even sandblasting in combination with silanizing $(16.20 \pm 3.01 \mathrm{MPa})$ did not reach bond strengths as high as using hydrofluoric acid etching with silanization [41]. Another in vitro study reported that silanization together with $9.5 \%$ hydrofluoric acid etching on the surface of feldspar-based ceramic bonded to composite improved bond strength dramatically $(46.9 \pm 6.6 \mathrm{MPa})$ but was not statistically significant compared to silanization only $(38.7 \pm 8.1 \mathrm{MPa})[42]$.

\subsection{Bond Strengths with Etching and Silanization Treatments with Water Storage}

It was observed in vitro that $9.6 \%$ hydrofluoric acid etching feldspar-based ceramic and silanizing bonded to resin composite produced mean shear bond strength of $11.97 \pm$ $0.47 \mathrm{MPa}$ after $24 \mathrm{~h}$ water storage at $37^{\circ} \mathrm{C}$. By adding a third surface treatment, viz. $50 \mu \mathrm{m}$ air particle abrasion, in addition to acid etching and silanization, the bond strength increased minimally to $12.34 \mathrm{MPa}$ [43].

Etching feldspar-based ceramics with concentrated hydrofluoric acid and then bonded to enamel resulted in a mean shear bond strength of $27.6 \mathrm{MPa}$. Thermo-cycling, ie. artificial aging of specimens transferring specimens between water baths of $5 \pm 2^{\circ} \mathrm{C}$ and $55 \pm 2^{\circ} \mathrm{C}$ for a number of cycles, 500 times decreased the bond strength to $21.4 \mathrm{MPa}$. A combination of both etching and silanizing resulted in mean shear bond strengths of $33.8 \mathrm{MPa}$ and thermo-cycling 500 times didn't reduce the bond strength significantly to 29.9 $\mathrm{MPa}$. The higher shear bond strength compared to other studies was attributed to the resin composite cement with a higher filler content that provided strength. Higher filler content reduces water sorption. It has been concluded that both etching and silanizing are crucial to achieving high bond strengths [44]. It has been reported that both hydrofluoric acid etching and silanization on lithium disilicate ceramics bonded to resin composites had significantly higher bond strengths than either treatments alone in vitro as shown in Table 1 [23].

However, etched and silanized leucite-reinforced ceramics bonded to resin composite did not improve the bond strength as much as silanizing treatment only as shown in Table 2 [23]. A bond strength of $49.7 \pm 11.9 \mathrm{MPa}$ was obtained compared to $27.2 \pm 4.8 \mathrm{MPa}$ [23] but the standard deviation was quite high for the study. However, the difference between the two studies was in [40] the ceramic surface was air abraded with $30 \mu \mathrm{m} \mathrm{Al}_{2} \mathrm{O}_{3}$ in addition to $9 \%$ hydrofluoric acid etching and the specimens were, interestingly, not subjected to water storage [23, 40]. Some other studies have found that etching with $8 \%$ hydrofluoric acid and silanization was not as effective as air abrading the ceramic surface with $50 \mu \mathrm{m} \mathrm{Al}_{2} \mathrm{O}_{3}$ followed by $8 \%$ hydrofluoric acid etching and silanizing. In fact, the researchers found a significant decrease in bond strength with etching and silanization only after thermo-cycling as shown in Table 3 [45]. Another in vitro experiment on the bond between resin-to-ceramic using leucite-reinforced

Table 1 Lithium disilicate ceramics bonded to resin composite water stored at $37^{\circ} \mathrm{C}$ for 30 days. Silanization with 3methacryloxypropyltrimethoxysilane

\begin{tabular}{ll}
\hline Treatments & Bond Strength/MPa \\
\hline $9.6 \%$ HF etched, silanized & $56.1 \pm 4.1$ \\
Silanized only & $30.1 \pm 5.3$ \\
$9.6 \%$ HF etched only & $41.7 \pm 6.7$ \\
\hline
\end{tabular}


Table 2 Leucite-reinforced ceramics bonded to resin composite water stored at $37^{\circ} \mathrm{C}$ for 30 days. Silanization with 3methacryloxypropyltrimethoxysilane

\begin{tabular}{ll}
\hline Treatments & Bond Strength/MPa \\
\hline $9.6 \%$ HF etched, silanized & $20.6 \pm 3.0$ \\
Silanized only & $27.2 \pm 4.8$ \\
$9.6 \%$ HF etched only & $9.9 \pm 1.2$ \\
\hline
\end{tabular}

ceramics found that treating the ceramic surface with $6 \%$ hydrofluoric acid etching and silanization resulted in similar bond strength as $30 \mu \mathrm{m}$ silica-coating and silanization, $10.19 \pm 3.1 \mathrm{MPa}$ and $10.17 \pm 3.1 \mathrm{MPa}$, respectively. Specimens were subjected to 7 day de-ionized water storage at $37^{\circ} \mathrm{C}$ [46].

\subsection{Some Conclusions}

Hydrofluoric acid etching and silanization can achieve the optimal bond strength in comparison to other etchants if the ceramic etched is feldspar-based but a few other studies demonstrated that other methods can also attain comparable bond strengths. Feldspar-based ceramics have a larger glassy phase that enables more etching that creates more porous structures and creates more micromechanical interlocking by the penetration of resin composite cement. Silanization can produce covalent bonding between the ceramic surface and the resin cement. However, too high concentration of hydrofluoric acid used for etching may have adverse consequences on the bond strength.

\section{Tribochemical Silica-Coating}

Dental ceramics with high crystalline content such as alumina and zirconia should be silica-coated prior to silanization because they do not contain a glassy phase for etching [47-49]. The tribochemical silica-coating method conditions the surface by depositing alumina particles coated with silica onto the substrate surface. The particles hit the surface causing a momentary local temperature as high as $1200^{\circ} \mathrm{C}$. The fresh silica layer fuses

Table 3 Shear bond strengths with and without air particle abrasion. Silanization with 3-methacryloxypropyltrimethoxysilane

\begin{tabular}{lll}
\hline Storage & $\begin{array}{l}\text { Bond strength when } \\
\text { etched and silanized// } \\
\text { MPa }\end{array}$ & $\begin{array}{l}\text { Bond strength, when } \\
\text { air abraded, etched, } \\
\text { and silanized/MPa }\end{array}$ \\
\hline $24 \mathrm{~h}$ & $22.7 \pm 4.9$ & $20.9 \pm 4.5$ \\
$24 \mathrm{~h}+2500$ cycles & $9.6 \pm 1.9$ & $17.4 \pm 2.0$ \\
of thermo-cycling & & \\
\hline
\end{tabular}

onto the substrate surface. Finally, a silane coupling agent (3-methacryloxypropyltrimethoxysilane) is applied to the surface to create hydrogen and covalent bonds between the substrate layer and the resin composite. The patented systems that are commercially available are Rocatec ${ }^{\circledR}$ system meant for dental laboratories $[30,50]$ and $\operatorname{CoJet}^{\circledR}$ for dentist's office [6, 49, 51].

Once resin bonded to alumina ceramics are silica-coated and silanized, shear bond strengths as high as $21.54 \pm$ 1.4 MPa can be obtained after 5000 times thermocycling between $+5^{\circ} \mathrm{C}$ and $+55^{\circ} \mathrm{C}$. Etching or sandblasting only resulted in shear bond strengths of $5.5 \pm 0.7 \mathrm{MPa}$ and $12.9 \pm$ 2.0 MPa, respectively [52]. A study on assessing the bond strength between alumina-reinforced feldspar ceramic and resin composite concluded that alumina-reinforced ceramics should be silica-coated and silanized to achieve a durable bond strength after thermo-cycling. Etching aluminareinforced ceramics with $9.5 \%$ hydrofluoric acid followed by silanization can result in higher bond strength than $30 \mu \mathrm{m}$ silica-coated alumina-reinforced ceramic followed by silanization initially. However, after dry and long term water storage at $37^{\circ} \mathrm{C}$ for 150 days followed by 12000 cycles in thermocycling, silica-coating with silanization can sustain a significantly higher bond strength than hydrofluoric acid with silanization as shown in Table 4 [29].

Before bonding resin to zirconia ceramics, zirconia must be treated by either air abrading the surface with alumina particles or silica-coated before silanization to achieve adequate bond strengths. Zirconia with no surface treatments and silanized resulted in low bond strength of $7.6 \pm$ 3.0 MPa. However, after $30 \mu \mathrm{m}$ alumina air abrasion followed by silanization, bond strength as high as $18.6 \pm$ 5.9 $\mathrm{MPa}$ was obtained [53].

\section{Current Research in Dentistry Regarding Resin Ceramic Bonding}

We may confidently claim that surface treatments are vital to achieving durable bonding and high bond strength between

Table 4 Alumina-reinforced ceramics bonded to resin composite before and after long term water storage. Silanization with 3methacryloxypropyltrimethoxysilane

\begin{tabular}{lll}
\hline Treatments & $\begin{array}{l}\text { Bond Strength- } \\
\text { no storage/MPa }\end{array}$ & $\begin{array}{l}\text { Bond strength after dry } \\
\text { storage at } 37^{\circ} \mathrm{C} \text { for } 150 \\
\text { days, and thermo-cycling } \\
12000 \text { times } / \mathrm{MPa}\end{array}$ \\
\hline $\begin{array}{l}\text { 9.5\% HF etched, } \\
\text { silanized }\end{array}$ & $19.8 \pm 3.8$ & $12.1 \pm 2.6$ \\
$\begin{array}{c}30 \mu \mathrm{m} \text { silica-coated, } \\
\text { silanized }\end{array}$ & $12.4 \pm 4.7$ & $14.5 \pm 3.1$ \\
\hline
\end{tabular}


resin and ceramic. Ceramics with the presence of a glassy phase should be acid etched and then silanized. High crystalline content ceramics should be silica-coated followed by silanization. Perhaps surprisingly, many reported in vitro studies do not test out different storage media other than the conventional storage conditions such as water storage or thermocycling. Some recent studies based on experimental silane coupling agents, such as 3-acryloxypropyltrimethoxysilane and 3isocyanatotriethoxysilane, suggest significantly improved bond strengths $[30,49,50,54-56]$ than those obtained with 3methacryloxypropyltrimethoxysilane. In general, future in vitro studies should consider the use of artificial saliva or food beverages as a storage media [57]. Also, far too many scientific reports use only 3-methacryloxypropyltrimethoxysilane $[6,11,30]$.

When comparing bond strengths among different studies, one should be very cautious because dissimilar ceramic types, varied concentration of acid etchant, selection of bond test method, different number of specimens, and distinctive storage methods and periods are used. Also, the absolute numerical bond strength values may be misleading; the comparison should be made to the control group behavior. A challenge remains: researchers should come up with a standardized method to make the various studies more comparable.

Open Access This article is distributed under the terms of the Creative Commons Attribution Noncommercial License which permits any noncommercial use, distribution, and reproduction in any medium, provided the original author(s) and source are credited.

\section{References}

1. Scheller-Sheridan C (2010) Basic guide to dental materials. Wiley-Blackwell, Ames

2. van Noort R (2007) Introduction to dental materials, 3rd edn. Elsevier, Philadelphia, PA

3. Roulet JF, Söderholm KJM, Longmate J (1995) J Dent Res 74:381

4. Yen TY, Blackman RB, Baez RJ (1993) J Prost Dent 70:224

5. Touati B, Miara P, Nathanson D (1999) Esthetic dentistry and ceramic restorations. Martin Dunitz, London

6. Stangel I, Nathanon D, Hsu CS (1987) J Dent Res 66:1460

7. Matinlinna JP, Lassila LVJ, Özcan M, Yli-Urpo A, Vallittu PK (2004) Int J Prosthodont 17:155

8. Canay S, Hersek N, Ertan A (2001) Effect of different acid treatments on a porcelain surface. J Oral Rehab 28:95

9. Della Bona A, Anusavice KJ, Mecholsky JJ (2003) Failure analysis of resin composite bonded to ceramic. Dent Mater 19:693

10. Darvell BW (2006) Materials science for dentistry, 8th edn. An own publication, Hong Kong

11. Matinlinna JP, Vallittu PK (2007) J Oral Rehab 34:622

12. Calamia JR, Vaidyanathan J, Vaidyanathan TK, Hirsch SM (1985) J Dent Res 64:296

13. Chen TM, Brauer GM (1982) J Dent Res 61:1439

14. Addison O, Marquis P, Fleming GJP (2007) Dent Mater 23:461

15. JADA (2002) J Am Dent Assoc 133:502

16. Cappelli DP, Mobley CC (2008) Prevention in clinical oral health care. Elsevier, St. Louis, p 199
17. Kukiattrakoon B, Thammasitboon K (2007) J Prost Dent 98:7

18. Tylka DF, Stewart GP (1994) J Prost Dent 72:121

19. Della Bona A, Anusavice KJ, Hood JAA (2002) Int J Prosthodont $15: 248$

20. Hayakawa T, Horie K, Kanaya H, Kobayashi T, Murata Y (1992) Dent Mater 8:238

21. Kato H, Matsumura H, Tanaka T, Atsuta M (1996) J Prost Dent 75:163

22. Ayad MF, Fahmy NZ, Rosenstiel SF (2008) J Prost Dent 99:123

23. Della Bona A, Anusavice KJ, Shen C (2000) J Adhes Dent 2:305

24. Linden CH, Rippe JM, Irwin RS (2006) Manual of overdoses and poisonings. Lippincott Williams \& Wilkins, Philadelphia

25. Hoffman RS, Nelson LS, Howland MA, Flomenbaum NE, Goldfrank LR (2007) Goldfrank's manual of toxicologic emergencies. McGraw-Hill, New York, pp 945-949

26. Hooshmand T, van Noort R, Keshvad A (2002) Dent Mater 18:179

27. Plueddemann EP (1991) Silane coupling agents, 2nd edn. Plenum, New York, NY

28. Puska M, Lassila L, Seppälä J, Vallittu P, Matinlinna J (2009) J Adhes Sci Techn 23:991

29. Özcan M, Valandro LF, Amaral R, Leite F, Bottino M (2009) Dent Mater 25:1477

30. Matinlinna JP, Lassila LVJ, Vallittu PK (2006) J Dent 34:436

31. Hooshmand T, van Noort R, Keshvad A (2004) Dent Mater 20:635

32. Brentel AS, Özcan M, Valandro LF, Alarça LG, Bottino MA (2007) Dent Mater 23:1323

33. van Ooij WJ, Zhu DQ, Prasad G, Jayaseelan S, Fu Y, Teredesai N (2000) Surf Engin 16:386

34. Barghi N (2000) Compend Contin Educ Dent 21:659

35. Özcan M, Matinlinna JP, Vallittu PK, Huysmans M-CDNJM (2004) Dent Mater 20:586

36. Blatz MB, Sadan A, Kern M (2003) J Prost Dent 89:268

37. Sorensen JA, Engelman MJ, Torres TJ, Avera SP (1991) Int J Prosthodont 4:17

38. Kamada K, Yoshida K, Atsuta M (1998) J Prost Dent 79:508

39. Simonsen RJ, Calamia JR (1983) J Dental Res 62:297

40. Magne P, Cascione D (2006) J Prost Dent 96:354

41. Suliman AA, Swift EJ, Perdigao J (1993) J Prost Dent 70:118

42. Lacy AM, Laluz J, Watanabe LG, Dellinges M (1988) J Prost Dent 60:288

43. Güler AU, Yilmaz F, Ural C, Güler E (2005) Int J Prosthodont $18: 156$

44. Stacey GD (1993) J Prost Dent 70:395

45. Thurmond JW, Barkmeier WW, Wilwerding TM (1994) J Prost Dent 72:355

46. de Melo RM, Valandro LF, Bottino MA (2007) Braz Dent J 18:314

47. Heikkinen TT, Lassila LVJ, Matinlinna JP, Vallittu PK (2009) Silicon 1:199

48. Lung CYK, Kukk E, Hagerth T, Matinlinna JP (2010) Appl Surf Sci 257:1228

49. Matinlinna JP, Heikkinen T, Özcan M, Lassila LVJ, Vallittu PK (2006) Dent Mater 22:824

50. Matinlinna JP, Lassila LVJ, Kangasniemi I, Vallittu PK (2005) J Dental Res 84:360

51. Heikkinen TT, Lassila LVJ, Matinlinna JP, Vallittu PK (2007) Acta Odontol Scand 65:241

52. Özcan M, Alkumru HN, Gemalmax D (2001) Int J Prosthodont 14:335

53. Yoshida K, Tsuo Y, Atsuta M (2006) J Bio Mater Res 77:28

54. Lung CYK, Matinlinna JP (2010) Silicon 2:153

55. Lung CYK, Matinlinna JP (2010) Silicon 2:163

56. Matinlinna JP, Lassila LV (2011) Dent Mater 27:273

57. Ho GW, Matinlinna JP (2011) J Adhes Sci Techn 2011 (in press) doi:10.1163/016942411X556042 